Implications for Guideline Developers/Users This study identified the performance and utility of the scoring guide as a useful guidance to Korean-AGREE II instrument users.

\section{P274 NEW NATIONAL GOVERNMENTAL GUIDELINE PROGRAM IN HUNGARY}

E Kis, E Nagy, E Dobos, E Karpati. National Institute for Quality- and Organizational Development in Healthcare and, Budapest, Hungary

\section{0:1136/bmjqs-2013-002293.235}

Background In Hungary officially 493 clinical practice guidelines (CPGs) were released by the Ministry of Health. Since most of the published guidelines were developed in 2005 and 2006, the updating process is necessary. In Hungary traditionally, professional associations develop guidelines. In lack of a dedicated guideline clearinghouse with an evidence-based methodological support function, mostly non-systematic, non-evidencebased or traditional methods were used when formulating recommendations.

Context To solve these anomalies, the National Institute for Quality- and Organisational Development in Healthcare and Medicines (NIQODHM) set up an expert group of evidence based methodologists to systematically revise the existing clinical guidelines and support the updating process. The expert group assessed the methodological quality of $90 \%$ of the existing CPGs by the AGREE instrument: most CPGs scored rather low on the stakeholder involvement, rigour of development, applicability, and editorial independence domains. Therefore our aim is to encourage the professional associations to improve these shortcomings.

Description of Best Practice The NIQODHM developed a webbased application to support this project and coordinates the participation of all relevant professional groups in the development teams. User-friendly tools for adaptation of evidence-based guidelines, based on internationally published methods and materials are developed and personal consultations are provided by the expert group of methodologists. To guarantee the independence of national guidelines, a regulated declaration process for Conflict of Interest is also introduced.

Lessons for Guideline Developers, Adaptors We do believe that methodological support tools will contribute to the development of higher quality and more applicable recommendations.

\section{P275 GUIDELINE-BASED QUALITY INDICATORS FOR CARDIAC REHABILITATION OF PATIENTS WITH ISCHEMIC HEART DISEASE IN JAPAN: USE OF A MODIFIED DELPHI TECHNIQUE FOR INDICATOR DEVELOPMENT}

${ }^{1} \mathrm{~S}$ Ohtera, ${ }^{2} \mathrm{~K}$ Ueshima, ${ }^{1} \mathrm{~T}$ Nakayama. 'Graduate School of Medicine/School of Public Health Kyoto University, Kyoto, Japan; ${ }^{2} E B M$ Research Center Graduate School of Medicine Kyoto University, Kyoto, Japan

\section{0:1136/bmjqs-2013-002293.236}

Background Cardiac rehabilitation improves quality of life and mortality in patients with ischemic heart disease, but it is underutilised and quality in practice is unknown. Quality indicators are increasingly used to quantify healthcare quality. In Japan, however, such indicators for cardiac rehabilitation have not been developed yet.

Objectives The purpose of this study was to develop quality indicators considering clinical circumstances in Japan.
Methods To determine quality indicator candidates, we systematically searched electronic databases and reviewed existing related guidelines indicators. Using a modified Delphi technique, a domestic multidisciplinary panel of ten experts was assembled for a face-to-face meeting. After panel members rated the candidates individually on a questionnaire, a final consensus was determined for each measure.

Results A literature search identified 894 clinical guidelines and 38 existing quality indicators. Some of them were excluded due to inconsistency with a priori criteria. Then, 26 guidelines and 16 indicators were selected to create a list of indicator candidates. The panel discussed 27 candidates: six indicators were adopted, one indicator was not adopted, 20 indicators were reconstituted into four indicators, and three new additional indicators were suggested. Consequently, 13 indicators were chosen. Discussion Guideline-based quality indicator development may be time-efficient and resource saving, but further methodology research is needed. We are planning a pilot test of these indicators at multiple facilities.

Implications for Guideline Developers/Users Guideline developers should take potential use as quality indicators into account for making recommendations.

\section{P281 APPLYING THE RE-AIM FRAMEWORK TO EVALUATE DISSEMINATION AND IMPLEMENTATION OF CLINICAL PRACTICE GUIDELINE FOR SEXUALLY TRANSMITTED INFECTIONS IN KOREA}

${ }^{1,2} \mathrm{H} \mathrm{Jo},{ }^{2,3}$ S Chang, ${ }^{2,4}$ Y Lee, ${ }^{2} \mathrm{E}$ Shin, ${ }^{1} \mathrm{M}$ Oh, ${ }^{1} \mathrm{H}$ Oh. ${ }^{1}$ Department of Health Management and Policy, Kangwon National University, Chuncheon, South Korea, ${ }^{2} T$ The Korean Academy of Medical Sciences, Seoul, South Korea; ${ }^{3}$ Department of Urology, Kyung Hee University School of Medicine, Seoul, South Korea; ${ }^{4}$ Department of Laboratory Medicine and Genetics, Soonchunhyang University College, Bucheon, South Korea

\section{0:1136/bmjqs-2013-002293.237}

Background Clinical practice guideline for Sexually Transmitted Infections were developed in 2011 by The Korean Urological Association supported financially by the Korean government. It is necessary to establish the theory-based strategy to disseminate and implement guideline more effectively.

Objectives To evaluate dissemination and implementation of clinical practice guideline for Sexually Transmitted Infections in primary health care in Korea.

Methods The RE-AIM framework in terms of reach, effectiveness, adoption, implementation and maintenance was applied. Structured questionnaire was formulated. Survey was performed by e-mailing to physicians working at primary health care clinics from 1st Nov - 30thNov 2012 and 305 physicians responded.

Results Of the total respondents, $37.5 \%$ answered 'Reach'- no problem for the accessibility of clinical guidelines, cognitive level, and adoption. For Effectiveness measurement, the use of practice guidelines would help the determination of the direction of treatment and communication with patients (52.2\%). For the Adoption-environment to apply clinical practice guidelines, there were no problems (50.6\%). For Implementation-the degree of application with Practice Guidelines, $17.8 \%$ of respondents frequently used the guidelines and, 91.0\% of respondents are willing to use them in the future. For Maintenance, $54.8 \%$ of respondents used the clinical practice guidelines for more than 6 months.

Discussion The reach has been low and even in the respondents with the guideline, the rate of clinical application has been low as well. 